\title{
Research on the Core Technology and the Development Tendency of Modern Precision Machinery Manufacturing
}

\author{
Pan Ming \\ Jiangsu Maritime Institute Jiangsu Nanjing 211170, China
}

\begin{abstract}
This paper delivers the research on the core technology and the development tendency of the modern precision machinery manufacturing. Precision technology development and application, to promote the machining precision of the whole mechanical manufacturing and technical level is of great significance while the long term even can improve mechanical product performance and the competitiveness. In recent years, China's machinery manufacturing industry also made some progress and the development, in this case, the machinery manufacturing industry in our country needs more precision manufacturing technology and precision machining technology. This paper proposes the new perspectives on the corresponding techniques that hold special meaning.
\end{abstract}

KEYWORD: Core Technology; Development Tendency; Precision Machinery; Modern; Methodology

\section{INTRODUCTION}

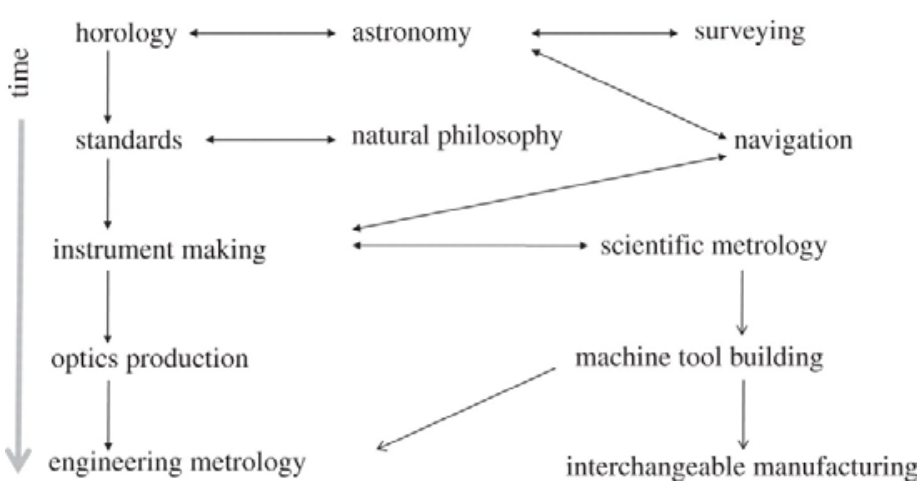

Fig. 1 The Developmental Path of the Precision Machinery Manufacturing

In the process of industrial boom, a change in the industrial field, mainly concentrated in the field of defence, aerospace, medical and electronics field, these areas in the process of change, more and more high to the requirement of precise small parts, in order to fully meet the requirements, in the tiny parts processing, the application of micro machine, which prompted the development of modern processing equipment in the direction of the miniaturization. Machinery manufacturing industry is the biggest characteristic of the relevance of the production technology, production of the product determines the production materials, production materials for further processing process parameters have different requirements and the corresponding stage of processing is based on the precision of the parts we need to determine the actual performance of the manufacturing.

As demonstrated in the figure one, we illustrate the developmental path of the precision machinery manufacturing, based on this issue we could summarize the functionality of the precision machinery manufacturing as the follows. (1) Precision machining technology is the key in the development of the modern weapons and equipment. The biggest demand precision machining technology is advanced weapons and equipment system while the military requirements directly promote the development of the ultra-precision machining technology. Precision machining technology is related to the national strategic status and reflects the important basic industry of national comprehensive national strength and it is the core of the measure of a country's manufacturing modernization degree. (2) Precision machining technology developed is to meet the basic need of modern high technology and advanced manufacturing technology. In order to follow the development of the mechanical manufacturing, the development of modern machinery manufacturing technology and precision machining technology is very urgent. The further development of mechanical manufacturing technology has been constantly, traditional mechanical manufacturing technology and precision machining technology is far behind the requirements of the times. Therefore, we must introduce the modern ma- 
chinery manufacturing technology and precision machining technology. (3) Precision machining is an important part of the foundation of modern high-tech technology. With the rapid development of science and technology, precision processing technology as the basis of high-tech development also has a growing, processing precision, processing efficiency in soon, in the future, precision machining technology is to a higher precision, higher efficiency, largescale and miniaturization direction (Obashi et al, 2016) (Ramstetter et al, 2014) (Ando et al, 2014).

In this paper, we conduct research on the core technology and the development tendency of modern precision machinery manufacturing. In the later sections, we will discuss the issues in detail.

\section{THE PROPOSED METHODOLOGY}

\subsection{Machinery Manufacturing Trend.}

At present, along with the high and new technology and modern management technology continuously introducing, the seepage and the fusion, the modern machinery manufacturing technology has become an organic combination of technology and management at a high level of comprehensive technology, manufacturing technology not only can measure a national science and technology progress and the development level that is also the focus of the competition between countries and technological prowess. Under this basis, the trend and further developmental orientation of the machinery manufacturing could be generally organized as follows (Chu et al, 2014).

$>$ The informationization trend. The three major elements of a manufacturing system: material, energy and information. The first two once had a dominant position in history. But with the advent of the era of knowledge economy, the elements of the information is rapid rise as the main factors restricting the modern manufacturing system, and has substantial impact on the manufacturing industry.

$>$ The digital trend. It can be seen from the discussion above, the development of mechanical manufacturing technology is the most important enabler is the widespread application of the computer technology, mechanical manufacturing technology of the important development direction is to digital.

$>$ Service as the trend. Era of industrial economy under the condition of mass production "with products as the center" is shifting to the "customeroriented" today. Modern manufacturing is the use of distributed, networked manufacturing system, with a large number of production under the condition of modern high efficiency and high benefit production to meet customer requirements of different kinds of products.

$>$ The development trend of integration. It is a product of the highly automated and integrated development of machinery manufacturing process by the original distributed processing step by step, into a complete integration, continuity processing and production.

$>$ High-tech trend. Today, the traditional mechanical manufacturing is to absorb the nutrition from other disciplines, and combined with other emerging industries, developed into a high technical content and added value of industry. There are many factors to promote development of the machinery manufacturing computer information technology, information technology, automatic control, management science, mechanical science and economic science etc.

\subsection{Precision Machinery Manufacturing Characteristics.}

In the current industrial development in the basic process of ultra-precision micro mechanical manufacturing technology is a very important technology. For research, the technology is very the attention of both at home and abroad, have been developed corresponding micro machinery manufacturing equipment, and small processing system, thus well completed the tiny parts processing, to promote the development of the industry.

Precise role in the development of composite processing technology in manufacturing technology and innovative significance could be organized as follows based on the literature review. (1) Precision compound processing technology is an effective means to enhance the core competitiveness of basic manufacturing technology. Machining accuracy of NC machine tool is one of the important indexes of enhancing core competitiveness of CNC machine tools, machining precision mainly depends on the precision machining method to improve and guarantee. Machining accuracy of NC machine tool is a "threshold" level of processing, processing accuracy requirement high accuracy requirement not only contains the machine itself, but also includes the protection characteristics of the machine tool accuracy requirement is high as which contains the high surface quality requirement. (2) Precision compound processing technology is an important means of solving basic problems in manufacturing technology. Process is the most active factor in the production, processing technology development, often from a technological breakthrough, now many of the processing problems, already can't use a single processing method to solve, but that need by the composite processing means to complete. (3) Precision compound processing technology is to make technology innovation strives for development in the emerging field of basic vision. Composite processing technology innovative, on the one hand, because compared with the traditional processing technology, new processing technology innovation is difficult, processing method of the compound, on the 
other hand that has a broad prospect, various combinations with the strong adaptability that could be reflected from the following figure.

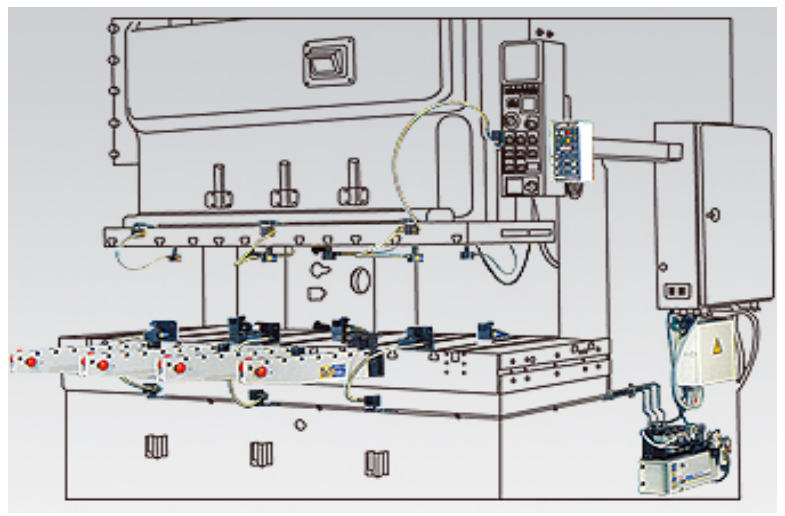

Fig. 2 The Sample Precision Machinery Manufacturing System

Now the high-tech, intelligent weapons have played a decisive role. High technology, intelligent weapons has the characteristics of high efficiency, high precision. Precision hot working technology, for example as is a key technology of manufacturing of weapon systems, including plastic, precision casting, precision, special heat treatment and special welding technology and precision hot working technology with short production cycle, low cost and parts with general good performance, product advantages of high reliability that attached great importance to by the countries all over the world.

\subsection{Intelligent and Automated Manufacturing.}

Machinery automation application in mechanical manufacture varies with further mechanical automation development. The application of mechanical automation gives strong technical support for the development of mechanical manufacturing can be generally summarized as the follows. (1) Integrated automation applications. The so-called integrated automation is the use of information collection to complete mechanical manufacturing technology. Integrated automation includes basic information statistics, computer aided calculation, manufacture, analysis, NC machining, and so on. Machinery manufacturing enterprise now has all the elements of enterprise and enterprise production and business activities to form a whole unity, enterprise overall optimization has been greatly increased production efficiency and basic labor efficiency. (2) Flexible automation applications. Flexible automation technology is not completely rely on automation, its technology is on the premise of flexible production as much as possible to perfect information system, make full use of computer management and enterprise efficiency. Flexible automation can strain the market change well. (3) The application of the virtual automation, the virtual automation using the in- formation technology and computer simulation technology to simulate mechanical manufacturing activities. Virtual automation technology to shorten the production cycle, increase the range of basic products, so it can deal with complex and changeable market needs.

The design of the machinery manufacturing intelligent, need from two aspects: one is mechanical manufacturing hardware and software of the intelligent design; Second, the machinery fault diagnosis and repair of intelligent, both be short of one cannot. Through intelligent means, can make in the work of engineering machinery manufacturing to analyze the internal and the external information, so as to judge whether machinery malfunction, found after failure can the inner system of a control device on the analysis of the fault in time and lay a foundation for troubleshooting. Based on the concept of intelligent mechanical manufacture, must establish on the basis of enough advanced hardware, this is a mechanical manufacturing intelligent to set up the premise of this proposition. At the same time, based on the design of the mechanical manufacturing, the development of corresponding software technology, such as numerical control technology, computer data analysis technology, etc., to make the machinery manufacturing of the hardware and software system can be in harmony are an organic whole, collaborative work, which benefits the improvement of machinery manufacturing operations and the facilitation of the overall and enhanced system.

Advanced manufacturing technology is a comprehensive competition ability of manufacturing the innovation is the inevitable choice of social development. At present, the advanced manufacturing technology rapid development, gradually formed the new and the high technology group, and after improving, the system has formed a sound system. However, subject to the limit of the basic national conditions of different countries, advanced manufacturing technology on the content and structure mode difference is very essential. Advanced manufacturing technology is latest stage of development, manufacturing technology is developed from the traditional manufacturing technology, not only keep the effective factors of manufacturing technology, in the past and to constantly absorbing all kinds of hightech achievements, and penetrated into all areas of production and its whole process.

\section{SUMMARY AND CONCLUSION}

In this paper, we conduct research on the core technology and the development tendency of modern precision machinery manufacturing. Fast development of machinery manufacturing industry in China has been and German side by side in the forefront of the world. Understand the basic principle of its 
manufacture process, to delve into the tip of the precision machining technology, we believe that the tireless efforts of researchers in related industries, will lead to further its development. In recent years, although the machining technology has made great development, traditional machining method and machining level already cannot satisfy requirement of the current product, therefore the development direction of mechanical processing technology should be toward the precision and ultra-precision, high speed and ultra-high speed and the direction of the automation, digitization, and can produce products that meet the quality. In the future, we will research more on these topics.

\section{REFERENCES}

Ando, Mitsuyo, and Fukunari Kimura. "Evolution of Machinery Production Networks: Linkage of North America with East Asia*." Asian Economic Papers 13.3 (2014): 121-160.

Bouzon M, Govindan K, Rodriguez C M T. Reducing the extraction of minerals: Reverse logistics in the machinery manufacturing industry sector in Brazil using ISM approach [J].

Chu, Won-Shik, et al. "Hybrid manufacturing in micro/nano scale: A Review." International Journal of Precision Engineering and Manufacturing-Green Technology 1.1 (2014): 75-92.

Obashi, Ayako, and Fukunari Kimura. "The Role of China, Japan, and Korea in Machinery Production Networks." International Economic Journal 30.2 (2016): 169-190.

Ramstetter, Eric D. "Wage Differentials between Foreign Multinationals and Local Plants and Worker Quality in Malaysian Manufacturing." Asian Development Review (2014).

Statistics U B O L. Import Price Index: Machinery manufacturing for Eastern Europe, Latin America, OPEC countries, and other countries in Asia, Africa, and the Western Hemisphere.

Sun, Yazhou, et al. "An integrated method for waviness simulation on large-size surface." Proceedings of the Institution of Mechanical Engineers, Part B: Journal of Engineering Manufacture. 